ANUARIO DE EstUdios MEDIEVALES 50/2, julio-diciembre de 2020, pp. 769-797

ISSN 0066-5061

https://doi.org/10.3989/aem.2020.50.2.05

\title{
DE ESCRIBAS Y ESCRITURAS EN DOCUMENTOS DEL MONASTERIO DE SAN SALVADOR DE OÑA (1187-1215)
}

\author{
SCRIBES AND SCRIPTS IN CHARTERS \\ OF THE MONASTERY OF SAN SALVADOR DE OÑA (1187-1215)
}

CONCEPCIÓN MENDO CARMONA

Universidad Complutense de Madrid https://orcid.org/0000-0003-3736-2649

\begin{abstract}
Resumen: El presente trabajo analiza las características escriturarias de los únicos seis escribas cuyos nombres figuran en los documentos del monasterio de Oña en el periodo cronológico 1107-1215, ámbito temporal en el que se produce, en Castilla, la última fase de evolución de la escritura pregótica y la consolidación de la gótica documental, y el paso del escribano que ejerce como simple autor material del documento al notario público. Así pues, se trata de analizar las características gráficas de estos scriptores que son ejemplo de este cambio.
\end{abstract}

Palabras clave: escritura pregótica; historia de la escritura; paleografía; monasterio de Oña; escribas.

Abstract: This paper analyses the handwriting of the last six scribes whose names appear in the charters of the monastery of Oña during the chronological period 1107-1215, which marked the final phase of the pre-Gothic style and the flowering of documentary Gothic. During that time, the scribe, who was only the material author of texts, developed into a public notary. Therefore, the aim of this study is to examine these scribes' graphic practices as they provide an example of this change.

Keywords: Pre-Gothic script; History of Writing; Palaeography; monastery of Oña; scribes.

\section{SUMARIO}

1. Introducción.- 2. Los escribas.-- 2.1. Miguel.- 2.2. Petrus Giraldi.- 2.3. Iohannes de Almazán.- 2.4. Magister Cristoforus.- 2.5. Ihoannes de Sotholuengo.-2.6. Dominicus Grecus.- 3. Consideraciones finales.- 4. Bibliografía citada.

\footnotetext{
* La investigación se ha realizado con el apoyo de los proyectos de investigación liderados por la Dra. María Jesús Torrens Álvarez, que se indican a continuación: "Primeras tradiciones de escritura romance en Castilla. Monasterios burgaleses", Ministerio de Ciencia e Innovación. Referencia: FF12012-36813 (01/01/2010-31/12/2013); "Estudio lingüístico de documentación cántabra y burgalesa (orígenes-siglo XV)", Ministerio de Economía y Competitividad. Referencia: FF12012-36813 (01/01/2013-31/12/2016); "El castellano norteño en la Edad Media. Estudio lingüístico de la documentación palentina”, Ministerio de Economía y Competitividad. Secretaría de estado de Investigación, Desarrollo e Innovación. Referencia: FFI2016-80230-P (01/01/2017-31/12/2020).
}

Citation / Cómo citar este artículo: Mendo Carmona, Concepción (2020), De escribas y escrituras en documentos del Monasterio de San Salvador de Oña (1187-1215), "Anuario de Estudios Medievales" 50/2, pp. 769-797. https://doi. org/10.3989/aem.2020.50.2.05

Copyright: (C) 2020 CSIC. Este es un artículo de acceso abierto distribuido bajo los términos de la licencia de uso y distribución Creative Commons Reconocimiento 4.0 Internacional (CC BY 4.0). 


\section{INTRODUCCIÓN ${ }^{1}$}

Este trabajo forma parte de una investigación más amplia sobre la escritura de los documentos de particulares de la zona del norte de Castilla, conservados en el Archivo Histórico Nacional, en el espacio de tiempo comprendido entre los siglos XII y el último tercio del XIII. Es este un periodo interesante, ya que se produce en Castilla la última fase de evolución de la escritura pregótica y la consolidación de la gótica documental que venía gestándose desde tiempo atrás ${ }^{2}$, además la transformación del escribano que ejerce como simple autor material del documento al notario público.

Bono, en su Historia del Notariado español, señala para el caso de León y Castilla entre los siglos IX y XII, que lo habitual era que los scriptores se encargasen de extender los documentos de los particulares por su capacidad no solo para escribir, sino también para redactar sus contenidos conforme a la tradición del derecho romano vulgar; en su mayoría clérigos, su intervención se limitaría a la mera puesta por escrito del hecho, lo harían ocasionalmente, casi siempre de forma anónima, sin suscribirlo o haciéndolo como un testigo más; aunque no faltan casos en los que sí se identifican como autores materiales del documento. A partir del s. XII se desarrolla el estamento de los scriptores profesionales, laicos en su mayoría, especialmente en las ciudades ${ }^{3}$. Aparecen escribas que suscriben añadiendo su topónimo de procedencia; en ocasiones, aunque no claramente, su dependencia del concejo iniciando el camino hacia la normalización del notariado público ${ }^{4}$.

Cuando la escritura carolina se impone en Castilla ha recorrido temporalmente un largo camino de desarrollo por lo que se encuentra en los estadios más avanzados de su evolución con marcados caracteres gotizantes. Stiennon habla de la evolución prolongada e imperceptible de la carolina gotizante que se muda en claramente gotizada en los inicios del s. XIII ${ }^{5}$. Por su parte, Strubbe señala otro fenómeno paleográfico que viene a acelerar el proceso de transformación de la carolina en la gótica:

Ya en la segunda mitad del siglo XII, se constata la aparición de una escritura más ligada y más rápida que se caracteriza por una oposición oscilante de la alteración pronunciada de la base de los

\footnotetext{
${ }^{1}$ Abreviaturas utilizadas: AHN Clero SR = Archivo Histórico Nacional, Clero Secular-Regular; $\mathrm{RAH}=$ Real Academia de la Historia.

${ }^{2}$ Sobre esta transformación de la escritura véase Ruiz 1993, pp. XXX-XXXII; Gimeno 1993.

${ }^{3}$ Bono 1979, vol. I-1, pp. 110-113.

${ }^{4}$ Calleja 2018, p. 30.

${ }^{5}$ Stiennon 1973, pp. 107-108.
} 
caídos de las letras hacia la izquierda equilibrada por el movimiento simétrico, hacia la derecha, de los astiles de las mismas. El dinamismo que esta oposición imprime anuncia ya una tendencia cursiva, prácticamente abandonada durante el largo reino de la carolina ${ }^{6}$.

Siguiendo a Nélis, el origen de esta cursiva diplomática reside en las actas emanadas de la cancillería pontificia, en concreto en las llamadas pequeñas bulas, que expedían los papas o los legados pontificios en la segunda mitad del siglo XII ${ }^{7}$.

En este estudio, en concreto, se quiere analizar la capacidad gráfica de seis scriptores que actúan en Oña en el periodo cronológico (1187-1215) y ejemplifican este momento de cambio gráfico. Su formación y procedencia son difíciles de determinar, pero se refleja una influencia notable de la cancillería pontificia en su escritura y son el eslabón entre los amanuenses precedentes y los notarios públicos.

Se ha elegido Oña porque este monasterio benedictino no solo era entonces una de las instituciones eclesiásticas más importantes de la Castilla primitiva y de la diócesis de Burgos, tanto por su riqueza como por el elevado número de iglesias dependientes de él, sino que gozaba de una posición cultural elevada como demuestra su famosa biblioteca. Por otro lado, su situación geoeconómica y la posesión de mercado propio en territorio de su jurisdicción facilitaban el trasiego de personas y mercancías que, con periodicidad semanal, se dirigían a celebrarlo ${ }^{8}$. Oña era, además, aduana destinada al registro de mercancías extranjeras que desembarcaban en los puertos del cantábrico para distribuirse por la Bureba y la Rioja ${ }^{9}$, y ruta de peregrinos a Santiago, por la que circulaban castellanos y extranjeros, gentes que deambulaban vendiendo y comprando productos. En conclusión, una zona con densidad de población y con un notable movimiento económico, que favorecía la actividad jurídica para su desarrollo y elaboración de pactos y contratos, fuesen puestos o no por escrito ${ }^{10}$.

\footnotetext{
${ }^{6}$ Strubbe 1961, tomado de Stiennon 1973, p. 110.

${ }^{7}$ Sobre este aspecto véase Nélis 1924, pp. 5-30.

${ }^{8}$ Sobre el mercado de Oña y los pueblos de su jurisdicción véase García de Valdeavellano 1931 y Ladero 1994; ambos autores se basan en los datos proporcionados por los fueros de 1176 y 1184, concedidos al monasterio por Alfonso VIII de Castilla, según la edición de los mismos realizada por Andrés 1915.

${ }^{9}$ Zabalza 2011, pp. 122-151; Serrano 2011, pp. 211-212.

${ }^{10}$ Sobre el del derecho mercantil en este periodo puede consultarse el trabajo de Berman 1996, pp. 349-373. Este mismo autor menciona el papel que incipientes notarios profesionales desempeñaban en las ferias y mercados del siglo XII italiano (Milano, año 1154), donde está documentada la presencia de los mismos, tanto de juristas profesionales como de notarios, acompañando a mercaderes y tratantes para asesorarlos y encargarse de las formalidades
} 
El objeto de estudio son solo doce diplomas ya que, de ciento cuatro documentos de aplicación del derecho privado, estudiados en el periodo cronológico comprendido entre 1107 y 1215 , solo esos doce mencionan a su autor material o responsable del mismo. Ninguno de ellos menciona su condición eclesiástica, aunque pudieran serlo. Sin embargo, el hecho de que su actividad se sitúa en las últimas décadas del s. XII, momento en que, como se ha explicado, tiene lugar el desarrollo de los profesionales de la escritura libres, que trabajan para monasterios, catedrales, concejos o particulares, nos hace pensar que estaríamos ante alguno de estos scriptores. Más aún cuando Oña se sitúa en el camino de Santiago, vía de tránsito económico por el que llegaban extranjeros que influían en todos los aspectos de la sociedad, y ruta cultural por excelencia. Sus nombres son: Miguel, Pedro Giraldo, Juan de Almazán, Juan de Solduengo, el Maestro Cristóbal, y Domingo "el griego".

\section{LOS ESCRIBAS}

\subsection{Miguel}

Figura en 1188 como escriba de la permuta de una tierra en Rioseras efectuada por el abad de Oña, Pedro, y el prior Rodrigo, señor de Tejada, a Gutier Peláez a cambio de que este les entregase dos tierras en Villaverde ${ }^{11}$. Se trata de una carta partida por ABC con el corte ondulado y situado en el lado izquierdo del pergamino, una posición poco frecuente que nos indica la distribución en columnas paralelas de ambos originales, disposición del texto característica de la producción libraria. Nada sabemos de este escriba ya que no aparece en otros documentos del monasterio de Oña. Emplea una escritura textual pregótica o gótica primitiva ${ }^{12}$, cuyas características más destacadas son la fractura de los trazos y el contraste entre los trazos finos y gruesos producido por el empleo de una pluma biselada, así como la sensación de compresión lateral de las palabras, sobre todo cuando dos letras comparten trazo ( $b b$ : cuadro $1, \mathrm{n} .^{\circ} 1$ ) o se encajan (co: cuadro $\left.1, \mathrm{n}^{\circ}{ }^{2} 2-3\right)$. Otro elemento característico es el arranque rematado de los trazos verticales de las letras (cuadro $1, n .^{\circ} 4$ ), no solo en los astiles sino también en los arranques y pies de $m, n, u$ e $i$. La

legales, así como la constitución durante los periodos de feria y mercado de tribunales comunitarios no profesionales encargados de resolver los litigios que pudieran plantearse, véase p. 363 de la cita. A otra escala, estas figuras podrían localizarse en los mercados castellanos coetáneos, incluidos los celebrados en Oña.

${ }^{11}$ AHN Clero SR, car. 277, n. ${ }^{\circ}$ 13; Álamo 1950, vol. I, p. 337.

${ }^{12}$ Ruiz 1993, p. XXX. 
morfología de las letras coincide exactamente con las descripciones dadas por los paleógrafos ${ }^{13}$ para este estadio de la escritura gótica por lo que omito la explicación pormenorizada de cada una de las letras y remito a la fig. $1^{14}$.

Por lo que se refiere a las reglas de Meyer, después de letra curva emplea $r$ redonda (cuadro $1, \mathrm{n} .^{\circ} 5$ ), pero no se da ningún caso de yuxtaposición de curvas contrapuestas. En cuanto a las ligaduras y abreviaturas se mantiene la característica unión carolina de st y se introduce una nueva $c t$ (cuadro 1, n. ${ }^{\circ}$ 6), así como el signo tironiano que se alterna con la forma $e t^{15}$.

Cuadro 1. Elementos góticos en la escritura de Miguel

\begin{tabular}{|c|c|c|}
\hline 1 & $b b$ & Illots \\
\hline 2 & co & cömutatio \\
\hline 3 & $p p$ & \\
\hline 4 & remate triangular de astiles & \\
\hline 5 & $r$ a continuación de letra curva. $o r$ & 1024 \\
\hline 6 & unión $c t$ & \\
\hline
\end{tabular}

${ }^{13}$ Millares 1983, vol. I, pp. 171-173; Marín, Ruiz 1984, vol. I, pp. 289-295; Tamayo 2012, pp. 347-363.

${ }^{14}$ Derolez 2006, pp. 60-65.

${ }^{15}$ Derolez 2006, p. 66. 
Suscribe Michael scripsit sin acompañar su nombre de signo alguno. De su buen hacer con la pluma es ejemplo la cuidada escritura, la disposición del texto en el pergamino, los márgenes delimitados mediante reglas de esticometría y la correcta separación interlineal.

La permuta pudo escriturarse en el lugar de Rioseras, pues figuran como testigos del acto el concejo y su alcalde, Martinus Martini. Miguel podría ser un profesional, laico o eclesiástico, que ejercía el oficio de escribano cuando era requerido para ello; recurre a una escritura textual para poner por escrito el contrato, hecho que pone de manifiesto la formación de algunos escribas en los dos tipos de escrituras: textual y documental, y el indiferente empleo de ellas. A finales del siglo XII, había copistas que desarrollaban su actividad al servicio de quienes los solicitaban e incluso formaban a otros en esta labor, por eso en los escritorios monásticos era frecuente que, trabajando con los monjes, hubiera empleados copistas a sueldo, laicos que trabajaban en parte en su propia casa y en parte para los mismos monasterios ${ }^{16}$.

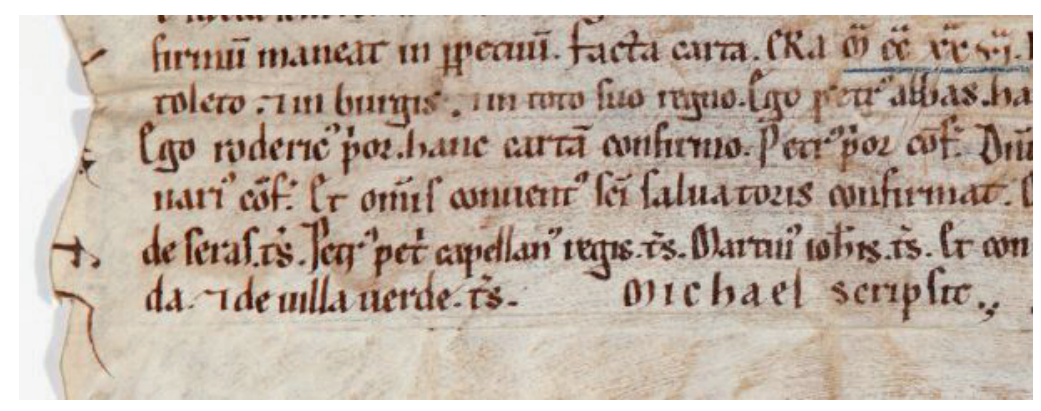

Fig. 1. Fragmento AHN Clero SR, car. 277, n. ${ }^{\circ} 13$.

\subsection{Petrus Giraldi}

Aparece por primera vez en la documentación de Oña en $1187^{17}$ y su última intervención data de 1215. En esos veintiocho años suscribe solo seis documentos ${ }^{18}$. Además, su mano copió uno de la reina Urraca, mientras que otro lleva su nombre, aunque no fue escrito por él. Es el escriba más prolífico de

\footnotetext{
${ }^{16}$ Hauser 1979, p. 216.

${ }^{17}$ Tomamos como referencia este primer documento por su autenticidad no cuestionada; con anterioridad a esta fecha, en 1152, se conserva una escritura de donación entre el abad Sancho Emercobio Nuñes y su esposa doña Enelina que parece una falsificación del s. XVII o principios del XVIII. AHN Clero SR, car. 275, n. ${ }^{\circ}$ 4bis; Álamo 1950, I, pp. 255-56. Citado por Puñal 2017 , p. 418, quien no cuestiona su autenticidad.

${ }^{18}$ Ver referencias en las notas que siguen.
} 
cuantos figuran en este periodo cronológico en la documentación del fondo de Oña y adapta su escritura a la solemnidad de los documentos que ejecuta.

Traslada al pergamino dos fueros otorgados por el abad Pedro; el primero de ellos en 1187 a los pobladores de Cornudilla ${ }^{19}$, el segundo en 1190 a los vasallos de Oña ${ }^{20}$. En ambos dispone el texto en cuarteles de forma que, en su posterior plegado, las dobleces del pergamino no puedan perjudicar el escrito. Es una técnica peculiar que llama visiblemente la atención y contribuye a solemnizar el documento además de favorecer su conservación en el tiempo. En primer lugar, se plegaba el pergamino en el modo en que debía ser conservado en el archivo ${ }^{21}$, convirtiéndolo en un pequeño paquete fácilmente transportable; una vez determinadas las marcas de los pliegues se escribía el texto saltándolas, confiriéndole un diseño gráfico peculiar al quedar organizado en cuadrículas o columnas, según el caso. La misma práctica se emplea una tercera vez en la copia de una carta de donación de la reina Urraca por la que entrega el monasterio de Santa Eufemia con todos sus bienes a San Salvador de Oña para el sostenimiento del monasterio de Valdecal, de su propiedad ${ }^{22}$. Desde el punto de vista jurídico, esta donación real se equipara a un fuero ${ }^{23}$, de ahí que Pedro Giraldo al copiarlo del original decidiera aplicarle también esta estructura en ocho cuadrículas para facilitar la conservación de la nueva copia.

El fuero de Cornudilla está dividido en doce porciones, el de Oña lo está en ocho (cuadro 2) y lleva líneas de continuidad uniendo las palabras cortadas por las dobleces ${ }^{24}$. Supongo que, debido a la importancia de su contenido y al continuo uso que se hacía de los documentos, era necesario preservar perfectamente el texto, evitando que la frecuencia en la apertura y cierre dañara el escrito situado entre los pliegues del pergamino, de ahí el sistema arbitrado para impedir toda merma de contenido que en un futuro pudiese dificultar su lectura y comprensión.

\footnotetext{
${ }^{19}$ AHN Clero SR, car. 277, n. ${ }^{\circ} 11$; RAH 1852, p. 79; Hinojosa y Naveros 1919, p. 87; Álamo 1950, vol. I, pp. 334-336; Barrero, Alonso 1989, p. 212.

${ }^{20}$ AHN Clero SR, car. 277, n. ${ }^{\circ}$ 18; RAH 1852 p. 168; Hinojosa y Naveros 1919, p. 90; Álamo 1950, vol. I, pp. 345-348; Barrero, Alonso 1989, pp. 345-348.

${ }^{21}$ Mendo 1998, p. 604.

${ }^{22}$ AHN Clero SR, car. 272, n. ${ }^{\circ}$ 16; Álamo 1950, vol. I, pp. 173-175. Para Monterde 1996, p. 157 es una copia del s. XIII en letra gótica; Ruiz 2003, p. 477, sigue a la autora anterior.

23 "Fuero: 4. ${ }^{\text {a }}$ Escritura de donación otorgada por algún señor o propietario a favor de particulares, iglesias o monasterios, cediéndoles tierras, posesiones y cotos, en todo o en parte; o simplemente de declaraciones, hechas por juez competente, del derecho que corresponde a alguno según ley o costumbre de la tierra o de los casos en que deben tener lugar las penas de las leyes", en Seix 1910, p. 638; también Martínez 1976, p. 528.

${ }^{24}$ La misma disposición del texto la observamos en algún documento de la cancillería de Alfonso VII conservado también en el fondo de Oña, AHN Clero SR, car. 273, n. ${ }^{\circ}$ 15; Álamo 1950, vol. I, pp. 203-204. Un estudio sobre la autenticidad de este documento puede consultarse en Lucas Álvarez 1993, p. 128.
} 
Giraldo escribe con cuidado, elegancia y belleza, denota en expresión de Cencetti, una "impronta cancilleresca", esto es el uso de formas artificiosas que pueden ser comunes a un grupo de escribas si estas se transmiten por uso y costumbre ${ }^{25}$. No se trata de una escritura diferente a los usos de la época, sino que se ejecuta adornando algunas letras de manera que visualmente se diferencien de la usual. Pedro Giraldo es buen conocedor del modelo escriturario utilizado en la cancillería papal, pues su letra es muy similar a la empleada en las bulas de Inocencio III, tanto en los remates de los astiles y caídos como en los adornos de ligaduras y signos de abreviación ${ }^{26}$; este escriba presenta los mismos rasgos. Se asemeja bastante a la denominada escritura de privilegios, calificada por J. Sanz Fuentes como "gótica cursiva fracturada formada" 27 , aunque cronológicamente sea anterior a la fecha tradicionalmente aceptada para la gótica en Castilla. Su elemento más peculiar son los ángulos que forman los astiles de las letras al prolongarlos curvándolos a la derecha en un trazo muy fino jugando así con el contraste entre finos y gruesos; otro tanto por lo que respecta a los caídos, pero en sentido inverso; es precisamente esta oposición la que aporta dinamismo a la escritura, dando sensación de cursividad cuando en realidad se trata de una escritura sentada ${ }^{28}$. Al mismo tiempo son estos rasgos los que imprimen al texto un carácter de excepcionalidad y solemnidad propios del mundo cancilleresco y, como he señalado antes, similar a la escritura pontificia de ese momento. Por lo demás, es de factura angulosa, comprimida, con correcta separación de palabras. Respecto a la morfología de las letras (cuadro 2) predomina el uso de la $d$ uncial; la $g$ de doble ojo; $r$ con caído prolongado formando ángulo hacia la izquierda, además de la redonda después de letra de trazo curvo; $s$ alta con un ojo en la parte superior al cerrar el trazo, empleada en inicio y medio de palabra, y de doble curva a final de palabra, siendo característica la prolongación hacia la izquierda del último trazo por debajo de la caja del renglón, que confiere a la letra un aspecto dinámico y la denominación $s$ de cola ${ }^{29}$.

${ }^{25}$ Cencetti 1997, p. 182.

${ }^{26}$ Sobre la influencia ejercida por la cancillería pontificia véase Sanz 2009, pp. 81-90.

${ }^{27}$ Sanz 2007, p. 119.

${ }^{28}$ Millares 1983, vol. I, p. 172 califica de minúsculas diplomáticas a las escrituras de las cancillerías castellano-leonesas coincidentes con el periodo cronológico en que trabaja este escriba; Puñal 2011, p. 294, vincula a este escriba con el maestro Giraldo, notario de la cancillería de Alfonso VII.

${ }^{29}$ Derolez 2006, p. 64. 
Cuadro 2. Elementos morfológicos reseñables de P. Giraldo

\begin{tabular}{|c|c|c|}
\hline LETRAS & FORMAS MINÚSCULAS & $\begin{array}{c}\text { FORMAS } \\
\text { MAYÚSCULAS }\end{array}$ \\
\hline$d$ & d & \\
\hline$g$ & & \\
\hline$r$ & & \\
\hline
\end{tabular}

En cuanto a las ligaduras, se mantiene la $s t$ y $c t$, apenas hay nexos salvo duplicación de $b b$ y $p p$ que forman encaje y la unión de curvas contrapuestas do y de, especialmente esta última, que comparten en muchas ocasiones trazo, cumpliendo la segunda regla de Meyer (cuadro 3). Es cierto que esta condición no siempre se practica, pues abundan los ejemplos en los que se escriben estas uniones manteniendo los trazos independientes y, por tanto, las letras separadas, pero se observa ya una tendencia acusada a yuxtaponer las curvas coincidentes como ocurre en la escritura gótica. 
Cuadro 3. Reglas de Meyer en la escritura de P. Giraldo

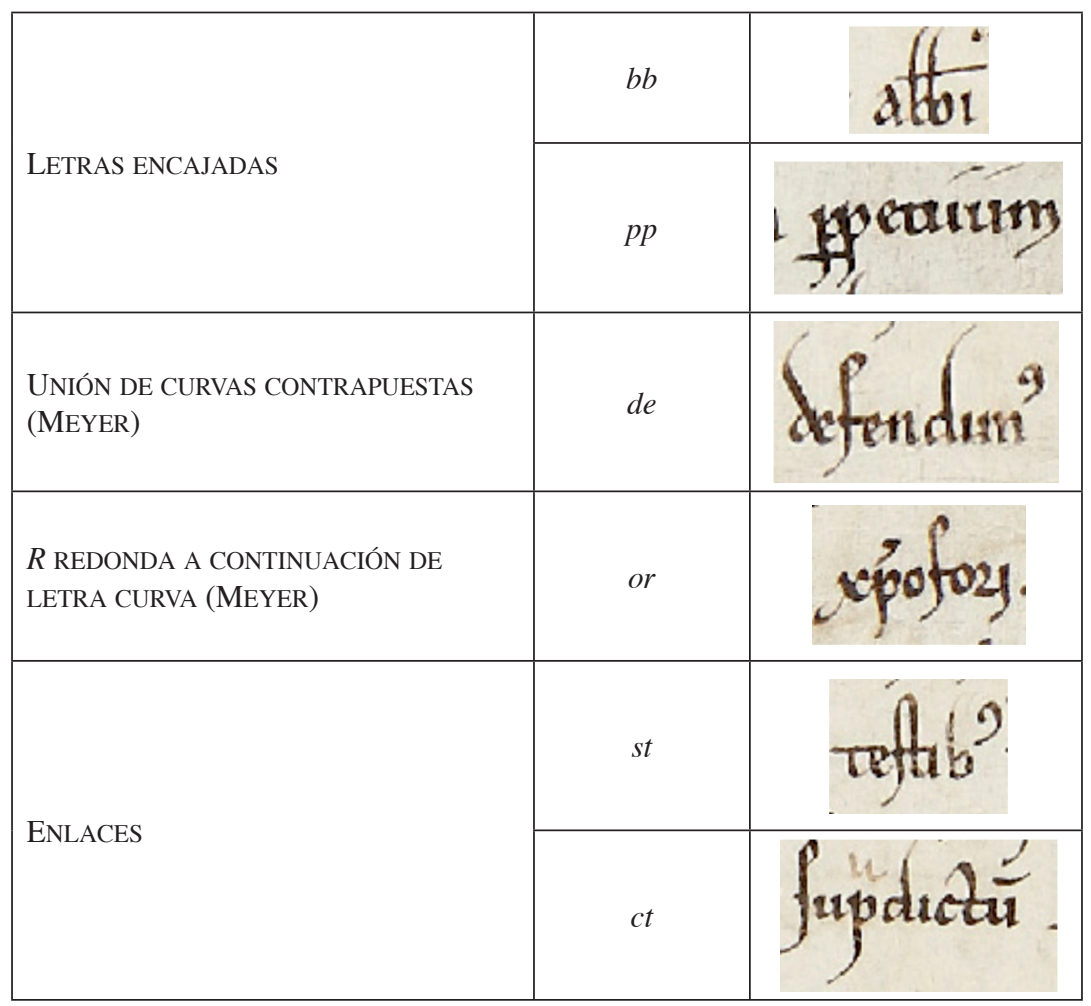

Los negocios jurídicos en los que interviene este escriba, además de los fueros mencionados ${ }^{30}$, se corresponden con dos donaciones y dos permutas. En un caso se trata de la donación pro pretio de la villa yerma de Encinillas que el abad de Oña concede a los moradores de Revilla y Cillaperlata, y se explicita en el texto que la tengan bajo el mismo fuero que sus otras heredades: illud forum quod de ceteris uestris hereditatibus habetis ${ }^{31}$. Implícitamente se concede estatuto jurídico a Encinillas, un mes después de que Alfonso VIII, durante su estancia en Burgos, confirmara al monasterio de Oña las donaciones por él otorgadas con anterioridad y reconociera como propios de Oña los pueblos de En-

\footnotetext{
${ }^{30}$ Sobre el fuero de Cornudilla y el concedido a los vasallos de Oña, véase Sánchez Domingo 2011b.

${ }^{31}$ El documento está fechado en 1187. AHN Clero SR, car. 277, n. ${ }^{\circ} 12$; Álamo 1950, vol. I, pp. 336-37; Martínez 1976, p. 542.
} 
cinillas y Castrillo ${ }^{32}$. La otra es una donación pro anima de Miguel Izquierdo al monasterio con la condición de ser enterrado en él ${ }^{33}$; en realidad es mucho más que una donación remuneratoria ${ }^{34}$, pues instituye una situación especial para Miguel dentro del monasterio de Oña, donde es acogido como un miembro de la comunidad pero gozando de unas libertades no comunes al resto de monjes: et habeas licentiam intrandi et exeundi ad postulandam portionem tuam et quandocumque uolueris eam comedas intus, quando uero uolueris defer tecum foris. Se podría decir que se trata de un privilegio o regla singular, que es también un fuero en el sentido restringido del término ${ }^{35}$.

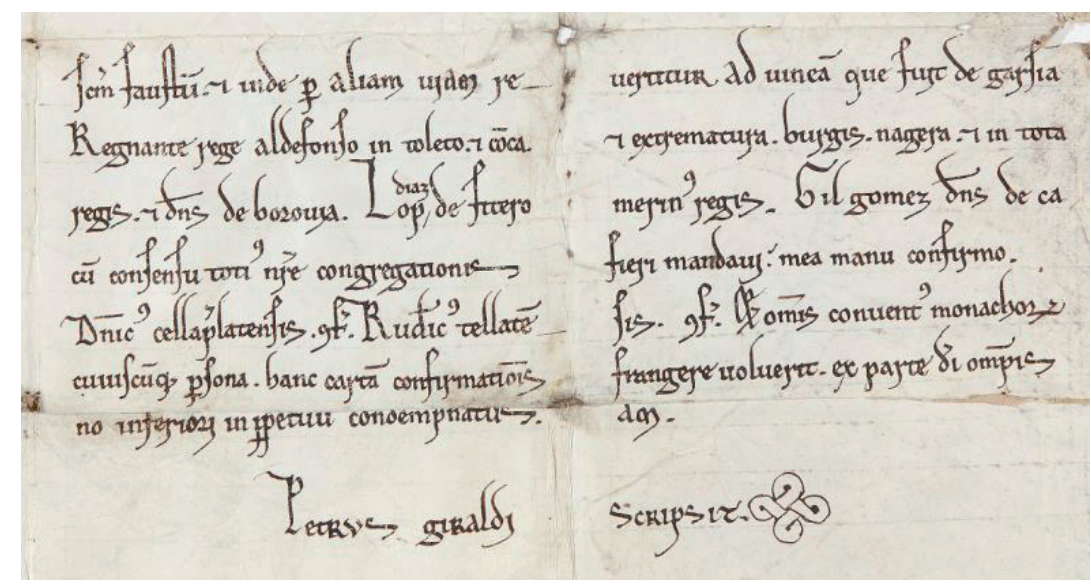

Fig. 2. Fragmento AHN Clero SR, car. 277, n. ${ }^{\circ} 11$.

En cuanto a las dos permutas que efectúa el monasterio de Oña, una está fechada en 1211, con Juan, abad de Olmos, María de Miguel y Beneta ${ }^{36}$; y la otra en 1215 realizada con Juan de Toves ${ }^{37}$. Estas dos escrituras no presentan la misma ejecución caligráfica que los otros documentos de este escriba. Pese a que su factura es cuidada, realiza aquí la escritura de forma usual, como se aprecia, sobre todo, en los remates de los astiles y caídos de las letras, ahora mucho menos artificiosos que en sus primeros escritos, y, en general, porque la escritura es más descuidada, como demuestra el olvido de alguna palabra que

\footnotetext{
${ }^{32}$ Serrano 2011, pp. 83-84,126; Álamo 1950, vol. I, pp. 328-329.

${ }^{33}$ El documento está fechado en 1190. AHN Clero SR, 277, n. ${ }^{\circ} 20$; Álamo 1950, vol. I, pp. 350-351.

${ }^{34}$ Álvarez 2005, pp. 166-167.

${ }^{35}$ Martínez 1976, p. 545.

${ }^{36}$ AHN Clero SR, car. 281, n. ${ }^{\circ}$ 18; Álamo 1950, vol. I, pp. 477-478.

${ }^{37}$ AHN Clero SR, car. 282, n. ${ }^{\circ}$ 6; Álamo 1950, vol. II, pp. 501-502.
} 
se incluye interlineada ${ }^{38}$. Asimismo, por el escaso espacio al final del texto que obliga a comprimir la suscripción del propio escriba ${ }^{39}$, una falta de previsión del espacio destinado al texto que no sucede en los documentos anteriores. Se observa también una mayor cursividad y la frecuente yuxtaposición de curvas contrapuestas, por lo que estaríamos ya ante una completa escritura gótica. Estas circunstancias podrían explicarse también por el tiempo transcurrido entre los primeros documentos de 1187 y estos últimos de principios del siglo XIII, pero me inclino a pensar que, más allá de la seguridad en la ejecución de la escritura que otorga el ejercicio de la profesión durante más de veinte años, hay una despreocupación interesada, puesto que se trata de negocios jurídicos de menor entidad (fig. 3). Se podría decir que entre los verdaderos fueros, los otorgados a Cornudilla y Oña, caligráficos y ostentosos, y estas permutas de buena escritura pero sobriamente ejecutadas, existe una gradación cualitativa consciente cuyo ejemplo son los que he considerado fueros en el sentido restringido de la palabra, cuya factura se encuentra entre los magníficos pergaminos y los algo descuidados; por esta razón señalaba más arriba que adapta su escritura a la naturaleza jurídica de los documentos que ejecuta.

En el documento de permuta fechado en 1211, hay que señalar un elemento diplomático novedoso para la época como es la aparición de la notificación inmediatamente después de la invocación verbal y seguida por la intitulación mediante el enlace quod: Notum sit presentibus et posteris quod ego Dominicus. Este cambio en el discurso diplomático anuncia la estructura característica del documento notarial bajomedieval como ha señalado Rojas Vaca $^{40}$. Si bien, la autora señala que esta innovación tiene escasa presencia en Burgos hasta 1256, se convierte en fórmula constante a partir de 1257 se documenta en el fondo del monasterio de Oña desde la segunda mitad del siglo XII en número suficiente para destacarlo como rasgo anticipado. Desde 1152 hasta 1215 esta estructura se repite en más de una treintena de $\operatorname{casos}^{41}$.

La permuta fechada el 1215, siendo posterior en el tiempo, mantiene el tenor documental tradicional en la documentación medieval: la invocación verbal inmediatamente seguida de la intitulación sin que medie ningún nexo. El hecho de que no se mantenga el esquema anterior en otro documento ulterior, con el mismo negocio jurídico y por el mismo autor, lleva a plantearnos que el scriptor hacía uso de los modelos documentales que tenía más a mano en lugar de formularios establecidos.

\footnotetext{
${ }^{38}$ AHN Clero SR, car. 281 n. ${ }^{\circ}$ 18; Álamo 1950, vol. I, pp. 477-478, línea 8 (nobis).

${ }^{39}$ AHN Clero SR, car. 281 n. ${ }^{\circ}$ 18; Álamo 1950, vol. I, pp. 477-478.

${ }^{40}$ Rojas 2001, pp. 363-367.

${ }^{41}$ Sirvan como ejemplo de ello: AHN Clero SR, car. 275, n. ${ }^{\circ} 4,21$; car. 277, n. ${ }^{\circ} 15$; car. 278 , n. ${ }^{\circ} 9,15,20$; car. 279, n. $^{\circ} 2,4-6,10,12-14,17,19-22$.
} 


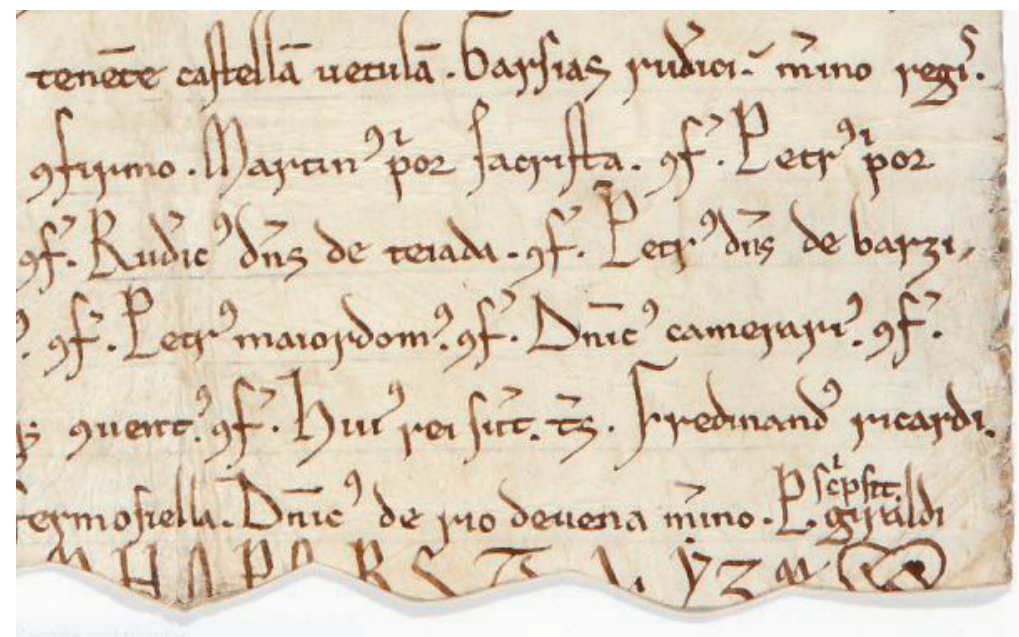

Fig. 3. Fragmento AHN Clero SR, car. 281, n. ${ }^{\circ} 18$.

Hay otro documento suscrito por Pedro Giraldo, pero no escrito por él. Presenta una escritura diferente de los documentos de la época; probablemente se trata de una copia bastante posterior que intentó imitar rasgos escriturarios propios del siglo XII. En 1198 Martín, Rodrigo y Alonso Álvarez venden a Oña una heredad ${ }^{42}$. En el documento figura la suscripción de Pedro Giraldo con una fórmula compleja y desconocida en sus otros escritos: Et ego Petrus Giraldi qui hanc carta feci signo meo iuxta prescriptum domini nostri regis perpetualiter more solito roboro et munio (signo con el monograma del escriba). No se corresponde con la habitual simplicidad de su suscripción: Petrus Giraldi scripsit. Posiblemente se incluyó esta fórmula con mención al precepto real para dar más autoridad al contenido jurídico del documento. El signo empleado en esta ocasión tampoco es el suyo; está formado por nueve cuadrados en los que incluye el nombre del escriba, sin embargo, el signo empleado en el resto de los documentos está formado por dos eses entrelazadas ${ }^{43}$. Llama la atención el amplio preámbulo diplomático de inicio: Rebus dilucide pestis. Ne proceso temporum obscuritatis obliuione obvolute humanum effugerent memoriam, solet per scriptorum seriem prudentiori captela suberini ${ }^{44}$, que no figura en otros documentos de la época ni de este escriba. ¿Por qué se suscribe con su nombre? Una explicación es que

\footnotetext{
${ }^{42}$ AHN Clero SR, car. 279, n. ${ }^{\circ} 3$; Álamo 1950, vol. I, pp. 385-386.

${ }^{43}$ Mendo 1997, pp. 216-227.

${ }^{44}$ Lafón 1989, p. 220.
} 
sea una refacción de un documento originalmente realizado por este escriba, o bien un falso que se le haya atribuido por haber sido un profesional de la escritura relevante.

Hay un documento más redactado por Pedro Giraldo en 1186, pero no se conserva en el fondo monástico de Oña, sino en el de Santo Toribio de Liébana, dependiente de aquél. Se trata de una escritura por la que el obispo de Palencia, Arderico, y Juan, abad de Oña, establecen el repartimiento de la propiedad de la Iglesia de San Esteban de Mieses. El primero se atribuía su propiedad junto con el monasterio de San Salvador de Campo de Muga, mientras que el abad oniense aseguraba que la misma, con todas sus pertenencias, era dominio del monasterio de San Martín y Santo Toribio de Liébana. Oña había recibido dicho monasterio de manos del conde don Gómez y de su mujer doña Emilia en $1083^{45}$. Mientras que el obispado de Palencia basaba sus derechos en que dicha iglesia pertenecía al monasterio de San Salvador, del que la diócesis era propietaria por privilegio concedido por Alfonso VIII en 18 de diciembre de $1185^{46}$.

Obispo y abad convienen en capítulo (cartam compositionis) repartírsela por mitad, junto con sus bienes. El documento fue puesto por escrito por Pedro Giraldo, cumpliendo el mandato conjunto de Arderico y de Juan, obispo y abad litigantes.

El documento se hizo por duplicado; se trata de un quirógrafo partido por ABC. De él se ha conservado el ejemplar custodiado en Santo Toribio de Liébana -la parte inferior-, así como dos copias en el cartulario de dicho monasterio, aunque en una de ellas se dice que el documento fue escrito por Juan de Almazán (Ihoannes de Almazán), scriptor del obispo palentino ${ }^{47}$. En el documento se explicita que las dos cartas, escritas con la misma forma, se dividen por el alfabeto: Huius autem compositionis due carte facte sunt sub uno tenore diuise per alfabetum, algo que no es frecuente en la época y que no se repite en ninguno de los documentos contractuales en los que figura como autor, también cartas partidas.

El convenio debe entenderse en el contexto de las disputas jurisdiccionales que tuvieron lugar en el siglo XII entre episcopado y monasterios; en un momento en el que el nuevo derecho eclesiástico comienza a ser aplicado para reforzar la autoridad episcopal frente a las exenciones

\footnotetext{
45 Álamo 1950, vol. I, pp. 318-320; González 1960, pp. 695-697.

${ }^{46}$ El privilegio se conserva en el Archivo de la Catedral de Palencia. San Martín Payo 1955, pp. 157-158; González 1960, pp. 766-767.

${ }^{47}$ AHN Clero SR, car. 1915, n. ${ }^{\circ}$ 7; Álamo 1950, vol. I, pp. 325-326. Hay dos copias más, véase Sánchez Belda 1948,pp. 143-144. De las dos copias del cartulario, una presenta variantes en su suscripción, adjudicando su autoría a Juan de Almazán.
} 
canónicas de las que disfrutan los monasterios ${ }^{48}$, y que coincide también con el momento en el que distintas diócesis delimitan su ámbito de influencia sobre aquéllas iglesias sobre las que pueden percibir el derecho a las tercias y otros beneficios económicos o de carácter litúrgico, caso de la palentina y de la burgalesa ${ }^{49}$.

Se ha mencionado más arriba que copia un documento de la reina Urraca. Asimismo, un Petrus notu Giraldi figura como escriba de un documento de la cancillería de Alfonso VII, fechado en 1124 y tachado de apócrifo por sus editores; Paradela le asigna la data de 1154 aunque sin poder asegurar su originalidad ${ }^{50}$. Si fuese esta la fecha correcta podría tratarse de nuestro Petrus Giraldi en los momentos iniciales de su formación. También, figura en 1186 como testigo de una permuta de documentos entre el cabildo catedral de Burgos y Juan Señal y su mujer Amelina, en el que ejerce de escribano Juan de Riolacedo, habitual en esta época escriturando documentos de la catedral. Finalmente quiero señalar que un personaje con el mismo nombre aparece como suscriptor de un fuero fechado en 1228 otorgado por Alfonso IX de León al burgo de Caldelas, hoy Castro de Caldelas, y considerado como el primer documento expedido por una cancillería real escrito en gallego ${ }^{51}$. No es posible afirmar que en todos los casos citados se trate de la misma persona, porque supondría un marco cronológico extremadamente amplio para la esperanza de vida en la época. Sí me atrevo a manifestar que tenía una sólida formación jurídica por los actos que documenta, y, de igual forma, una excelente preparación y dominio de la escritura; este nivel de estudios correspondía en la época a quienes aprendían en las escuelas catedralicias y ejercían temporal o permanentemente al servicio de la cancillería episcopal o real.

${ }^{48}$ Sánchez Domingo 2011a, pp. 412.

${ }^{49}$ Serrano 2011, pp. 346-385. La delimitación de los límites de la diócesis palentina y su organización territorial y señorial ha sido estudiada por Martínez 1988, p. 378; Reglero de la Fuente 2004, pp. 9-13.

${ }^{50}$ Paradela 1933-1935, vol. X, pp. 113-114.

${ }^{51}$ Memorias para la vida del Santo Rey Don Fernando, dadas a luz con apéndices y otras ilustraciones por Don Miguel de Manuel Rodríguez, bibliotecario primero de los Reales estudios de Madrid quien las dedica a la Reina Nuestra Señora que Dios guarde, 1700, p. 363 , texto cuyo original se conserva en el Archivo Ducal de la Casa de Alba y que ha sido editado varias veces, entre ellas por González 1944, pp. 624-628. 


\subsection{Iohannes de Almazán}

Aparece en la documentación de Oña como notario de la sentencia que el obispo de Palencia, Arderico, dicta para resolver el pleito entre los monasterios de San Salvador y Sahagún, y suscribe como notario del obispo ${ }^{52}$. No es de extrañar que no aparezca ninguna vez más en los documentos del fondo oniense y que su escritura pertenezca al tipo cancilleresco, puesto que forma parte de la curia episcopal palentina. Las características de su escritura coinciden con las ya destacadas para Petrus Giraldi. Convendría añadir que la influencia de la escritura de la cancillería papal es grande, como se observa en los adornos de los enlaces ct y st (instrumentum; monasterii; facta; castella) e, incluso, en la ejecución de la palabra eiusdem uniendo en un mismo trazo $s$ y $d$ (cuadro 4). Este adorno es propio de la cancillería pontificia que, en los documentos más solemnes, para representar el grupo ct y st enlazaba ambas letras por medio de una gran ligadura elevada sobre la línea de escritura y utilizaba una especie de ocho abierto por la base como signo general de abreviación, mientras que, en los documentos menos solemnes, estas se indicaban con un simple trazo y los enlaces $c t$, st se ejecutaban sin ligadura superior ${ }^{53}$.

\section{Cuadro 4. Adornos en los enlaces st y $c t$}

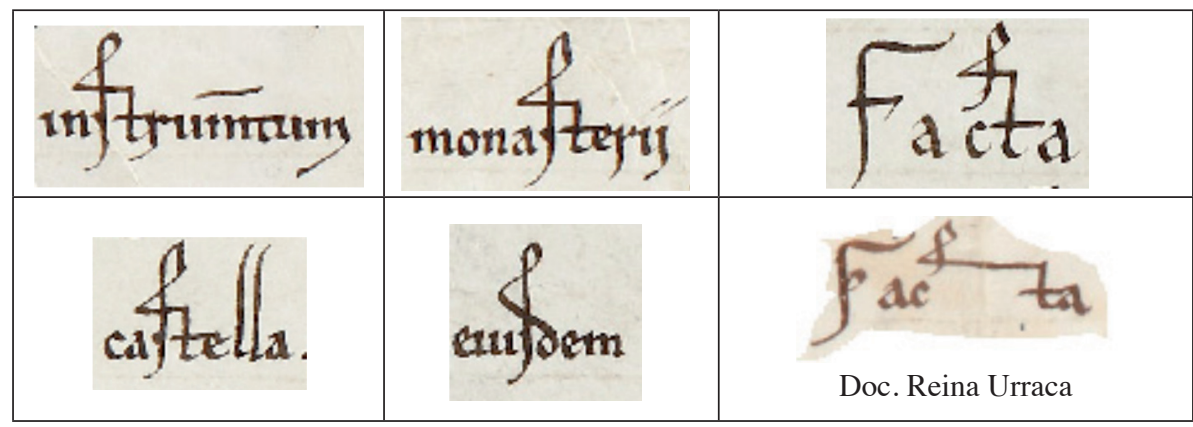

Las coincidencias escriturarias con Giraldo se ponen también aquí de manifiesto, puesto que este utiliza el mismo adorno en la palabra Facta de la copia del documento de la reina Urraca (cuadro 4). Que ambos escribas han recibido la misma formación y se desenvuelven en el mundo cancilleresco eclesiástico es claro (fig. 4).

${ }^{52}$ AHN Clero SR, car. 278, n. ${ }^{\circ} 8$; Álamo 1950, vol. I, pp. 363-365, para quien el documento es copia coetánea del original: AHN Clero SR, leg. 1915, n. ${ }^{\circ}$ 10; Sánchez Belda 1948, pp, 149-159.

${ }^{53}$ Delisle 1887, p. 121. 
Arderico, nacido en Milán, fue obispo de Sigüenza de 1178 a 1184, año en que pasaría a ocupar la diócesis palentina hasta 1208. En palabras de P. Linehan, es el primero de una serie de juristas procedentes de Francia e Italia que, atraídos por la generosidad de Alfonso VIII, se asentaron en Palencia, centro cultural de Castilla durante su reinado ${ }^{54}$. Juan de Almazán como su notario, colabora en las tareas de administración de la diócesis y forma parte de la casa episcopal, centro intelectual rico y poderoso en el siglo XII, y cuyos miembros estaban a menudo dotados de una educación avanzada ${ }^{55}$.

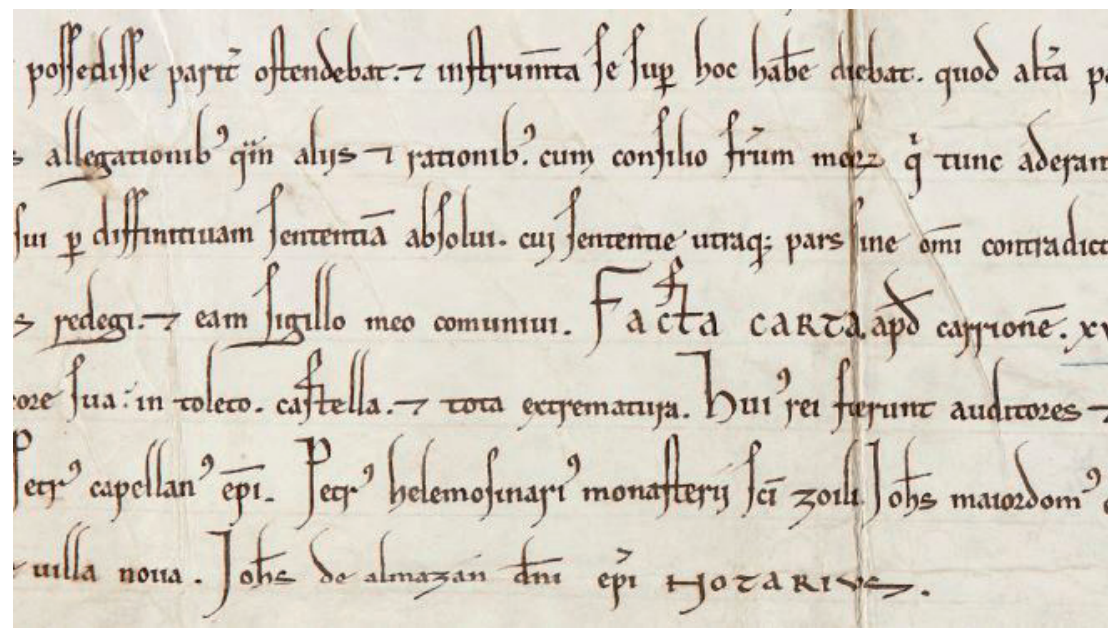

Fig. 4. Fragmento AHN Clero SR, car. 278, n. $^{\circ} 8$.

\subsection{Magister Cristoforus}

Este es el escriba de los fueros concedidos por Pedro, abad de Oña, a los moradores de Solduengo y Quintana Marzán ${ }^{56}$ en 1193. Conviene resaltar el título que reivindica en la suscripción del documento, en la que deja atribuido su nombre y su responsabilidad: Magister Cristoforus scribi fecit eam (fig. 5). Estos fueros no han sido trasladados al pergamino por un escriba cualquiera, sino por un maestro con un grado mayor de formación en leyes y en el arte de la confección de documentos. Julio González,

\footnotetext{
${ }^{54}$ Linehan 2012, pp. 332-334.

${ }^{55}$ Haskins 2013, p. 48.

${ }^{56}$ AHN Clero SR, car. 278, n. ${ }^{\circ}$ 14; Hinojosa y Naveros 1919, p. 95; Álamo 1950, vol. I, pp. 371-372; Barrero, Alonso, pp. 371-372.
} 
al hablar del desarrollo cultural en la Castilla de la segunda mitad del siglo XII, destaca la existencia de un cada vez mayor número de titulados superiores -maestros-, facultados para alcanzar dignidades y desempeñar profesiones que exigen competencia, principalmente para el derecho y la enseñanza; títulos que, para el caso de Castilla, debían adquirirse fuera del país $^{57}$. El mismo autor señala la relación entre la dignidad eclesiástica y el cargo cancilleresco y determina que el canciller suele ser obispo, arcediano o maestrescuela; el notario, canónigo o maestro; y el escriba, un simple clérigo $^{58}$.

La escritura de este maestro es una pregótica, afacetada, de astiles y caídos pronunciados que acusa el contraste entre el canon de la letra y la largura de estos, resultando una escritura estilizada. Las características morfológicas más destacadas son: $a$ con copete, propio ya de la escritura gótica; empleo indistintamente de la $d$ recta y uncial; el caído de la $g$ se ejecuta de forma horizontal a la caja de escritura; $s$ final de cola; la $r$ prolonga el trazo vertical formando un caído que se remata curvándose a la izquierda, como todos los caídos de las letras, mientras que los astiles lo hacen muy ligeramente a la derecha. No se cumple la regla de Meyer de yuxtaponer las letras con curvas contrapuestas, pero si la $r$ redonda después de letra curva. En general, una escritura muy cuidada, estilizada y con algunos adornos como en la ejecución de la $f$ (cuadro 5).

\footnotetext{
${ }^{57}$ González 1960, vol. II, pp. 629-634, detecta la presencia de maestros en Segovia (años 1148,1162 y 1194), en Osma (1195, 1196 y 1197), Sigüenza (donde identifica a un maestro Giraldo en 1187), Cuenca (1185 y 1204), Toledo (donde se distinguen personas que tienen el título - $1163,1164,1194,1219$ - junto a otros que desempeñan un magisterio efectivo - 1205 y 1213-, Nájera (1171) y Burgos $(1185,1200,1207,1209$ y 1215), pero sobre todo en el ámbito de Palencia, donde acabaría instituyéndose la Universidad, formada en su origen con profesores franceses e italianos, y las poblaciones relacionadas con ella como Valladolid, ciudad en la que destaca la escuela de Santa María que fue regida por maestros entre 1152$1159,1171-1190$ y 1215 , y además por varios cancilleres reales. En Palencia documenta maestros ya desde 1165, aunque la fundación de la universidad se data con posterioridad a 1211, algunos de ellos juristas como Aldefranco o Fornelino, este último venido de Italia, tan reputado experto que Inocencio III le encargó que juzgase el pleito entre el obispo de Burgos y el abad de Oña en 1215.

${ }^{58}$ González 1943, pp. 164-65; Ostos 1994, p. 109.
} 
Cuadro 5. Elementos morfológicos reseñables de M. Christoforus



El maestro Cristóbal que ejercería como responsable de la formación de los monjes, se responsabilizaría de la escrituración de este documento debido a la naturaleza jurídica del mismo. La legislación eclesiástica sobre la educación clerical fue muy clara y directa desde el siglo XI en adelante y condujo en España a la consolidación de las escuelas catedralicias y diocesanas como instituciones ampliamente desarrolladas 
y con importante vida académica; el historiador Julio González fecha en 1171 la de Burgos ${ }^{59}$. A finales del siglo XII no es extraño pensar que existieran en Castilla profesionales de la pluma instruidos en tales escuelas, que ya por entonces habían relegado a las escuelas monásticas a un papel marginal, como sucedía en otras partes del occidente europeo; ya se ha mencionado la existencia de copistas y escribas que desarrollaban su actividad al servicio de quienes los contrataban e incluso formaban a otros en estas labores ${ }^{60}$.

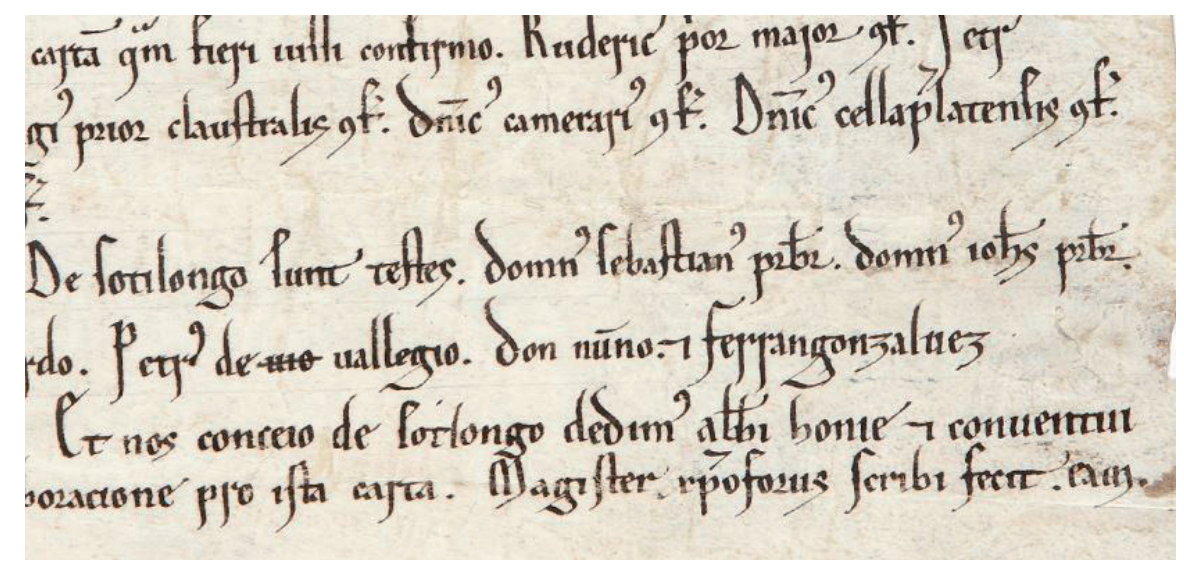

Fig. 5. Fragmento AHN Clero SR, car. 278, n. ${ }^{\circ} 14$.

\subsection{Ihoannes de Sotholuengo}

En 1204 se escritura la noticia de las heredades que el abad Pedro de Oña adquirió de don Pedro Oriolo en Navas. Se conservan dos pergaminos que corresponden a manos distintas, uno de ellos autoría de Juan de Solduengo ${ }^{61}$ y el otro de un escriba anónimo ${ }^{62}$. Según Álamo ${ }^{63}$, el primero es copia de este último; las diferencias entre ellos no afectan al contenido, únicamente hay variaciones en la grafía de algunas palabras. La escritura de ambos documentos es similar en cuanto a la morfología de las letras, aunque son diferentes en el canon, el peso y en la forma de su ejecución. En el pri-

\footnotetext{
${ }^{59}$ Bartolomé 1987, p. 289.

${ }^{60}$ Haskins 2013, pp. 47-53.

${ }^{61}$ AHN Clero SR, car. 280, n. ${ }^{\circ} 13$.

${ }^{62}$ AHN Clero SR, car. 280, n. ${ }^{\circ} 15$.

${ }^{63}$ Álamo 1950, vol. I, pp. 429-430.
} 
mer caso, nos encontramos con una escritura fracturada, de canon reducido en contraste con los prolongados astiles y caídos, ambos con tendencia a la verticalidad. Pese a sus remates ligeramente curvos a derecha e izquierda respectivamente, podemos considerarla pregótica con las mismas características señaladas para el escriba anterior tanto por la forma de las letras como por el cumplimiento de las reglas de Meyer (fig. 6). Por el contrario, el documento anónimo presenta una escritura mucho más ligera, de un cuerpo excesivamente pequeño, y astiles y caídos muy prolongados y con pronunciados remates curvos que le proporcionan sensación de movimiento, de cursividad, a lo que también contribuyen las formas más redondeadas en el conjunto de las letras. Además, sí se cumple la unión de curvas contrapuestas en la mayoría de los casos. Podría definirse de escritura gótica, anterior a la gótica cursiva mal llamada letra de albalaes, como se observa incluso en la duplicación de ss que aparece en algunas palabras. En mi opinión, sería esta la copia, algo posterior en el tiempo por presentar una escritura más evolucionada que la anterior y corregir algunas palabras con respecto al documento suscrito por Juan (cuadro 6).

En cuanto al hecho escriturado, la denominación "noticia" se otorgaba en la Edad Media a los documentos no contractuales que tenían valor jurídico probatorio, al ser una declaración posterior al propio acto jurídico y por tanto sin carácter dispositivo. No sabemos si los documentos de esas adquisiciones existieron o nunca se escrituraron, pero parece que la noticia, muy empleada en época medieval, permitía garantizar la autenticidad de los actos como el documento-testimonio de época romana ${ }^{64}$, refrendando la validez de una práctica jurídica y preservando su memoria cuando faltaran los testigos conocedores de los hechos. Esta legitimación no podía realizarla un mero scriptor, era responsabilidad de un escriba con formación jurídica.

${ }^{64}$ Neira 2005, p. 39. 
Cuadro 6. Elementos morfológicos reseñables de Ihoannes de Sotholuengo



Juan, como revela en su firma, procede de Solduengo, villa perteneciente al dominio de Oña, y se responsabiliza de la confección material del documento: Iohannes de Sotholuengo qui me scripsit, no se presenta como profesional de la escritura pero asume su autoría. A principios del siglo XIII se documentan en Burgos scriptores laicos, como el famoso Juan de Riolace$\mathrm{do}^{65}$. Podría ser este un ejemplo más de escriba que trabaja al servicio de los particulares o del concejo.

\footnotetext{
${ }^{65}$ Bono 1979, vol. I, p. 113.
} 




Fig. 6. Fragmento AHN Clero SR, car. 280, n. ${ }^{\circ} 13$.

\subsection{Dominicus Grecus}

En 1206 Domingo "el griego" escritura la permuta realizada entre el monasterio de Oña y un matrimonio ${ }^{66}$. Su escritura es similar a la de los escribas antes estudiados: astiles prolongados y ligeramente curvados hacia la derecha en $b, d, h, l, s$ y caídos que se curvan hacia la izquierda, incluso en letras que debieran descansar sobre la línea del renglón, como ocurre con la $r$ que alarga y remata con adorno hacia la izquierda; se consigue así dar sensación de dinamismo a una escritura sentada. Es, en general, una escritura más redondeada que las de los escribas anteriores y no emplea la yuxtaposición de curvas contrapuestas (fig. 7).



Fig. 7. Fragmento AHN Clero SR, car. 281, n. ${ }^{\circ} 3$.

${ }^{66}$ AHN Clero SR, car. 281 , n. ${ }^{\circ} 3$; Álamo 1950, vol. I, pp. 442-443. 
Una característica de Domingo, que no se observa en los otros personajes, es el empleo de la grafía $c$ para el sonido $z$; lo emplea dos veces en la palabra faça.

Este documento de intercambio de tierras en Cornudilla sigue el tenor documental innovador que he comentado más arriba en la permuta escrita por Petrus Giraldi, la inclusión de la notificación entre la invocación verbal y la intitulación, estructura que anuncia uno de los cambios en la estructura diplomática que caracteriza al notariado público. Pero, además, presenta otra novedad, la mención a la aposición del sello: Et ego Petrus, Honiensis abbas, ut factum nostrum firmum permaneat sigillum meum apono. Como ha puesto de manifiesto Puñal desde la segunda mitad del s. XII comienzan a aparecer nuevas fórmulas de validación que incluirán el sellado de los documentos ${ }^{67}$.

\section{CONSIDERACIONES FINALES}

1. A excepción de Miguel, cuya escritura semeja a la gótica textual de módulo, unidad y peso acusado, el resto de escribas presentan una forma escrituraria similar que se puede considerar gótica en muchas de sus características, como se ha ido comentando en cada caso, aunque no se cumplan todas las reglas de Meyer o no de forma rigurosa. Son todas ellas escrituras sentadas pero con sensación de movimiento por el juego de astiles y caídos curvados hacia la derecha e izquierda respectivamente. Esta escritura se ejecuta en distintos niveles: cancilleresco o usual en función del negocio jurídico a que se aplique. Durante esta etapa de la historia de la escritura oniense, se asiste a una doble influencia que va a caracterizar la escritura de los documentos conservados: por un lado, la imitación de los modelos textuales de la gótica y por otro, la emulación de los modelos de la cancillería papal, la denominada minúscula cancilleresca, y de la gótica anglosajona.

2. Respecto a la formación de estos escribas a mi juicio procederían de las escuelas catedralicias que para esta época habían adquirido un gran desarrollo, llegando a superar en muchos casos a las escuelas monásticas, como es el caso de Palencia y probablemente de Burgos. Esto explicaría la homogeneidad en la escritura y los adornos de las letras, similares a la escritura de la cancillería papal, en los documentos de mayor relevancia jurídica. En estos centros, además de quienes deseaban realizar carrera en la iglesia, acudían cuantos querían adquirir una formación en letras, algunos de ellos predecesores de los escribanos de concejo. Como se ha dicho al principio de este

${ }^{67}$ Puñal 2017, p. 420. 
estudio, Oña está situada en la ruta francesa del camino de Santiago, ruta de peregrinos procedentes de toda Europa y, sobre todo, de mercancías y mercaderes que necesitaban acudir a profesionales de la escritura para la realización de sus negocios, rogatarios laicos dispuestos a trabajar para quien lo solicitase.

3. Este grupo de rogatarios son ejemplo de los cambios que desde las últimas décadas del s. XII anuncian la consolidación de la escritura gótica documental y de las transformaciones, lentas pero firmes que se van introduciendo en el tenor documental, que advierten de la implantación del notariado público unos años después.

\section{BIBLIOGRAFÍA CITADA}

Álamo, Juan del (1950), Colección Diplomática de San Salvador de Oña (8221284), Madrid, Consejo Superior de Investigaciones Científicas.

Álvarez Coria, Enrique (2005), La teoría de los contratos en Castilla (Siglos XIII al XVIII), Madrid, Colegio de Registradores de la Propiedad y Mercantiles de España.

Andrés, Luis (1915), Fueros y privilegios concedidos por Alfonso VIII, al monasterio de San Salvador de Oña, en los años 1176 y 1184, "Revista de Archivos, Bibliotecas y Museos" 19/7-8, pp. 128-136.

Barrero García, Ana María; Alonso Martín, María Luz (1989), Textos de Derecho local español en la Edad Media. Catálogo de fueros y costums municipales, Madrid, Consejo Superior de Investigaciones Científicas.

Bartolomé Martínez, Bernabé (1987), Escuelas de Gramática, en Diccionario de Historia eclesiástica de España, Suplemento I, Madrid, Consejo Superior de Investigaciones Científicas, pp. 285-300.

Berman, Harold J. (1996), La formación de la tradición jurídica de Occidente, México, Fondo de Cultura Económica.

Bono, José (1979), Historia del Derecho notarial español, vol. I-1, Madrid, Junta de Decanos de los Colegios Notariales de España.

Calleja Puerta, Miguel (2018), Institución notarial y transferencias culturales en los reinos de Castilla y León antes de 1250, en Escritura, notariado y espacio urbano en la Corona de Castilla y Portugal (siglos XII-XVII), Gijón, Trea, pp. 15-32.

Cencetti, Giorgio (1997), Lineamenti di storia della scritura latina, Bolonia, Pàtron Editore.

Delisle, Léopold (1887), Forme des abréviations et des liaisons dans les lettres des papes au XIII' siècle, "Bibliothèque de l'École des Chartes" 48, pp. 121-124. 
Derolez, Albert (2006), Palaeography of Gothic Manuscript Books, Cambridge, University Press.

García de Valdeavellano, Luis (1931), El mercado. Apuntes para su estudio en León y Castilla durante la Edad Media, "Anuario de Historia del Derecho Español" 8, pp. 201-405.

Gimeno Blay, Francisco (1993), «De scriptura gothica». Algunos ejemplos a propósito de sus inicios en la península ibérica, "Scriptorium: Revue internationale des études relatives aux manuscrits" 47/2,pp. 115-125.

González, Julio (1943), Regesta de Fernando II, Madrid, Consejo Superior de Investigaciones Científicas - Instituto Jerónimo Zurita.

González, Julio (1944), Alfonso IX, vol. II, Madrid, Consejo Superior de Investigaciones Científicas - Instituto Jerónimo Zurita.

González, Julio, (1960), El reino de Castilla en la época de Alfonso VIII, vol. II, Madrid, Consejo Superior de Investigaciones Científicas - Escuela de Estudios Medievales.

Hasknins, Charles Homes (2013), El renacimiento del siglo XII, Barcelona, Ático de los libros.

Hauser, Arnold (1979), Historia social de la literatura y el arte, vol. I, Barcelona, Editorial Labor.

Hinojosa y Naveros, Eduardo (1919), Colección de documentos para la historia de las instituciones de León y Castilla, ss. X-XIII, Madrid, Junta de Ampliación de Estudios e Investigaciones Científicas.

Ladero Quesada, Miguel Ángel (1994), Las ferias de Castilla. Siglos XII a $X V$, Madrid, Comité Español de Ciencias Históricas.

Lafón Álvarez, Luisa (1989), Arenga hispana: una aproximación a los preámbulos documentales de la Edad Media, "Historia, Instituciones y Documentos" 16, pp. 133-232.

Linehan, Peter (2012), Historia e historiadores de la España medieval, Salamanca, Ediciones Universidad de Salamanca.

Lucas Álvarez, Manuel (1993), El Reino de León en la Alta Edad Media. V. Las cancillerías reales (1109-1230), León, Centro de Estudios e Investigación San Isidoro.

Marín Martínez, Tomás; Ruiz Asencio, José Manuel (dirs.) (1984) Paleografía y Diplomática. Madrid, Universidad Nacional de Educación a Distancia.

Martínez Díez, Gonzalo (1976), Fueros locales en el territorio de la provincia de Santander, "Anuario de Historia del Derecho Español" 46, pp. 527-608.

Martínez Díez, Gonzalo (1988), Restauraciones y límites de la Diócesis palentina, "Publicaciones de la Institución Tello Téllez de Meneses" 59, pp. 351-386. 
Memorias para la vida del Santo Rey Don Fernando dadas a luz con apéndices y otras ilustraciones por Don Miguel de Manuel Rodríguez, bibliotecario primero de los Reales estudios de Madrid quien las dedica a la Reina Nuestra Señora que Dios guarde (1700), Madrid, imprenta de la Viuda de Don Joaquín Ibarra.

Mendo Carmona, Concepción (1997), La suscripción altomedieval, "SIGNO. Revista de Historia de la Cultura Escrita" 4, pp. 207-229.

Mendo Carmona, Concepción (1998), El pensamiento archivístico medieval. Una página de la historia de la cultura a través del fondo documental de la Catedral de León, en Pensamiento medieval hispano. Homenaje a Horacio Santiago-Otero, vol. I, Madrid, Consejo Superior de Investigaciones Científicas - Consejería de Educación y Cultura de la Junta de Castilla y León - Diputación de Zamora, pp. 591-626.

Millares Carlo, Agustín (1983), Tratado de Paleografía española, 3 vols., Madrid, Espasa-Calpe.

Monterde Albiac, Cristina (1996), Diplomatario de la reina Urraca de Castilla y León (1109-1126), Zaragoza, Anubar Ediciones.

Neira Faleiro, Concepción (2005), La notitia dignitatum. Nueva edición crítica y comentario histórico, Madrid, Consejo Superior de Investigaciones Científicas.

Nélis, Hubert (1924), De l'influence de la minuscule romaine sur l'écriture aux XII e ${ }^{e}$ XIII ${ }^{e}$ siècles en Belgique, "Bulletin de l'Institut historique belgue de Rome" 3, pp. 5-30.

Paradela, Benito (1933-1935), Documentos del monasterio de Montederramo, "Boletín de la Comisión Provincial de Monumentos de Orense" 10, pp. 113-114.

Puñal Fernández, Tomás (2011), El testimonio escrito de la vida privada: scriptores y notarios en San Salvador de Oña (ss. XI-XIV), en San Salvador de Oña: Mil años de Historia, Oña, Fundación Milenario San Salvador de Oña - Ayuntamiento de Oña, pp. 292311.

Puñal Fernández, Tomás (2017), Estrategias políticas en torno a la implantación del notariado en el norte de Castilla: la abadía de San Salvador de Oña, "En la España Medieval" 40, pp. 409-431.

Ostos Salcedo, Pilar (1994), La cancillería de Alfonso VIII, rey de Castilla (1158-1214), una aproximación, "Boletín Millares Carlo" 13, pp. 101-136.

Real Academia de la Historia (1852), Colección de fueros y cartas pueblas de España, Catálogo, Madrid, Imprenta de la Real Academia de la Historia. 
Reglero de la Fuente, Carlos (2004), La Edad Media, en Historia de las Diócesis españolas, 19. Iglesias de Palencia, Valladolid y Segovia, Madrid, Biblioteca de Autores Cristianos.

Rojas Vaca, María Dolores (2001), Los inicios del notariado público en el reino de Castilla. Aportación a su estudio. "Anuario de Estudios Medievales" 31/1, pp. 329-395.

Ruiz Albi, Irene (2003), La reina doña Urraca (1109-1126). Cancillería y colección diplomática, León, Centro de Estudios e Investigación San Isidoro.

Ruiz Asencio, José Manuel (1993), Colección Documental del Archivo de la Catedral de León. VIII (1230-1269), León, Centro de Estudios e Investigación San Isidoro.

Sánchez Belda, Luis (1948), El cartulario de Santo Toribio de Liébana, Madrid, Patronato Nacional de Archivos Históricos.

Sánchez Domingo, Rafael (2011a), Conflictos de jurisdicción con la mitra burgense. El caso de San Salvador de Oña, en San Salvador de Oña: Mil años de historia, Burgos, Fundación Milenario de Oña - Ayuntamiento de Oña.

Sánchez Domingo, Rafael (2011b), Dominio y jurisdicción de la abadía de Oña, "Circunstancia: revista de ciencias sociales del Instituto Universitario de Investigación Ortega y Gasset” 24.

San Martín Payo, Jesús (1955), Catálogo del Archivo de la Catedral de Palencia , "Publicaciones de la Institución Tello Téllez de Meneses" 13, pp. 129-165.

Sanz Fuentes, Josefa (2007), La escritura gótica documental en la Corona de Castilla, en Paleografía II: Las escrituras góticas desde 1250 hasta la imprenta. Actas de las V Jornadas de la Sociedad Española de Ciencias y Técnicas Historiográficas, Oviedo, Universidad de Oviedo, pp. 107-126.

Sanz Fuentes, Josefa (2009), La influencia de la cancillería pontificia en las cancillerías reales castellano-leonesas, en Roma y la Península Ibérica en la Alta Edad Media. La construcción de espacios, normas y redes de relación, León, Universidad de León - Göttingen, Akademie der Wissenchaften zu Göttingen, pp. 81-90.

Seix, Francisco (ed.) (1910), Enciclopedia Jurídica Española, vol. XVI, Barcelona, Francisco Seix Editor, pp. 638-643.

Serrano, Luciano (2011), El obispado de Burgos y Castilla primitiva desde el siglo V al XIII, vol. II, Madrid, Instituto Valencia de Don Juan, reimpr. Ed. Maxtor (1 . edición, 1935).

Stiennon, Jacques (1973), Paléographie du Moyen Âge, París, Armand Colin. 
Tamayo, Alberto (2012), Historia de la escritura latina e hispánica, Gijón, Ediciones Trea.

Strubbe, Egied I. (1961), Grondbegrippen van de Paleografie del Middeleeuwen, 2 vols., Gante, Scory - Scientia (2. ${ }^{\text {a edición). }}$

Zabalza, Manuel (2011), El documento fundacional del monasterio de Oña (1011). Estudio y comentario en San Salvador de Oña: Mil años de Historia, Burgos, Fundación Milenario San Salvador de Oña - Ayuntamiento de Oña.

Fecha de recepción del artículo: abril 2019

Fecha de aceptación y versión final: mayo 2020 